\title{
A relação eu-tu na educaÇÃo à partir do Ensino de Filosofia
}

\author{
Nathalia de Oliveira*
}

Bernardo já estava uma árvore quando eu o conheci. Passarinhos já construíam casa na palhado seu chapéu.

Brisas carregavam borboletas para o seu paletó.

E os cachorros usavam fazer de poste as suas pernas.

Quando estávamos todos acostumados com aquele bernardo-árvore ele bateu asas e avoou.

Virou passarinho.

Foi para o meio do cerrado ser um arãquã. Sempre ele dizia que o seu maior sonho era ser um arãquã para compor o amanhecer.

(BARROS, Manoel. 2010, p.476).

\section{RESUMO}

Este trabalho consiste na análise do papel do ensino de filosofia na reinvenção do espaço escolar na perspectiva da alteridade. Proponho pensarmos o Ensino de Filosofia como espaço de reflexão do processo escolar, para além da história da filosofia desenvolvendo protagonismo reforçando os lugares de fala e decisão de nossas(os) discentes, os maiores interessados nesse processo. Refletindo a escola, e esses modos de fazer o ensino de filosofia, por meio da ética da alteridade, do diálogo e da valorização dos direitos humanos. Um caminho encontrado neste trabalho para repensar nossos lugares no mundo é o uso da arte, a arte como instrumento na sala de aula, em escolas que nos faltam recursos,

* Mestranda em Ensino de Filosofia na Universidade Federal do ABC. Supervisora Bolsista do subprojeto de Ciências Humanas no Programa Institucional de Bolsa de Iniciação à Docência (PIBID). Diretora de Relações Pedagógicas da APROFFIB. Especialista em Ensino de Filosofia pela Universidade Federal de São Carlos (2019). Licenciada em Filosofia pela Universidade Metodista de São Paulo (2014). Professora e Coordenadora de area da Rede Estadual de Ensino. Estudante bolsista do subprojeto de Filosofia no PIBID de 2012 à 2014.

Revista Páginas de Filosofia, v. 9, n. 2, p. 201-219, jul.-dez. 2020 
e espaços diferenciados, a arte está inserida em nosso cotidiano em diversos lugares e aspectos.

Palavras-chave: Educação. Alteridade. EU-TU. OUTRO. Relações. Direitos Humanos.

\section{Abstract}

This work consists of analyzing the role of philosophy teaching in the reinvention of the school space in the perspective of otherness.

I propose to think of Philosophy Teaching as a space for reflection on the school process, in addition to the history of philosophy, developing protagonism by reinforcing the places of speech and decision of our students, who are most interested in this process. Reflecting the school, and these ways of teaching philosophy, through the ethics of otherness, dialogue and the enhancement of human rights.

One way found in this work to rethink our places in the world is the use of art, art as an instrument in the classroom, in schools that lack resources, and differentiated spaces, art is inserted in our daily lives in different places and aspects. Keywords: Education. Alterity. ME YOU. OTHER. Relations. Human rights.

\section{INTRODUÇÃo}

0 presente trabalho consiste na análise do papel do ensino de filosofia na reinvenção do espaço escolar na perspectiva da alteridade e dos direitos humanos.

Proponho a pensarmos o Ensino de Filosofia como espaço de reflexão do processo escolar, para além da história da filosofia desenvolvendo protagonismo reforçando os lugares de fala e decisão da comunidade estudantil, parte mais interessada nesse processo.

Segundo Evandro Ghedin:

o ensino de filosofia é o espaço de encontro entre o saber filosófico, o saber pedagógico e outros saberes, que travam, no interior da escola, uma relação complexa e polêmica. (GHEDIN, 2002, p. 226). 
Então é muito importante que o corpo docente (da area de filosofia) tenha essa formação pedagógica, pois a reprodução de uma história da filosofia de nada contribuiria com as/os estudantes. Não faz sentido estudar Emmanuel Lévinas, se não for para repensar nossa postura diante do que ele problematiza. De que modo então a alteridade pode possibilitar uma reinvenção escolar por meio do ensino de filosofia? Fazer nos pensar nas interdependencias de vidas?

Falo a partir de escolas públicas do Grande ABC. Escolas com um modelo institucional já conhecido por nós, como estudantes ou professoras e professores.

Da escola com problemas já diagnosticado por Michel Foucault, Theodor Adorno, bell hooks, Paulo Freire e outras pessoas.

A academia não é o paraíso, mas o aprendizado, é um lugar onde o paraíso pode ser criado. A sala de aula com todas suas limitações continua sendo ambiente de possibilidades. Nesse campo de possibilidades, temos a oportunidade de trabalhar pela liberdade, exigir de nós e de nossos camaradas uma abertura da mente e do coração que nos permite encarar a realidade ao mesmo tempo em que, coletivamente, imaginemos esquemas para cruzar fronteiras, para transgredir. Isso é a educação como prática da liberdade (HOOKS, 2013.p. 273.)

Junot Cornélio Matos em seu texto "Filosofando sobre o ensino de filosofia", reforça a necessidade de repensarmos o ensino de filosofia, e o papel da escola; pois é próprio da filosofia colocar a si mesma em questão.

Com o retorno da filosofia para as escolas em 2008, tínhamos em mente que a questão chave estava, principalmente, na formação do professores. Esses sim! Precisavam de sólida formação pedagógica. (MATOS, 2015, p.369).

Não perguntávamos pela escola. Afinal de contas ela já estava lá, e a Filosofia, certamente, traria sopros de renovação para seu interior. Hoje, sabemos que a formação é uma condição necessária, porém insuficiente. (MATOS, 2015, p.369)

Matos, nos mostra que a preocupação já é outra, ela agora está atrelada as possibilidades de atuação na escola, não apenas no seu 
conteúdo, diríamos que a questão é mais política que pedagógica; mais filosófica que epistemológica. (MATOS, 2015, p. 370). Portanto, a maior preocupação hoje é - fazer uma filosofia na escola, pensar a filosofia como scholé (MATOS, 2015, p. 370), apoiado no pensamento de Jan Masschelei e Maarten Simons de que a escola - pode ser reinventada. (MATOS, 2015, p. 370).

Se pensarmos na instituição escolar ao longo da história, percebemos que a Educação sempre foi ferramenta de controle para os governos. De acordo com os ideais, os governantes sejam eles eleitos democraticamente (vide Fernando Henrique Cardoso ao vetar o retorno da filosofia e sociologia da grade curricular) ou ditadores, reestruturaram, reorganizaram as escolas ao seu modo. Michel Foucault já nos alertou sobre isso em sua obra "Vigiar e Punir; para o filósofo, a escola é uma das "instituições de sequestro", comparando-a com o hospital, o quartel e a prisão e tem por objetivo moldar suas condutas, disciplinar seus comportamentos e formatar o que e como pensamos. Desconsiderando subjetividades e direitos.

Focando nas disciplinas de Filosofia e Sociologia vemos que estas entram e saem de cena de acordo com o governo vigente, saem do Currículo Nacional na Ditadura, retoma na possibilidade de integrar o currículo escolar no contexto da Diretas Já em 1983/84 (decisão que cabia a escola, optar por uma, as duas ou as três: Filosofia, Sociologia e Psicologia). Na década de noventa é vetado o projeto de retorno destes componentes curriculares, pelo então presidente e ironicamente sociólogo, Fernando Henrique Cardoso. Retomando apenas em 2008 no governo de Luís Inácio Lula da Silva, com o Ministro da Educação Fernando Haddad.

Na eleição de 2014 pudemos acompanhar os debates sobre as reformas do ensino médio, e muitas vezes pré-candidatos a presidencia da república mencionaram a possível retirada do Ensino de Filosofia e Sociologia, inclusive pela então Presidente (e Candidata ao segundo mandato) Dilma Rousseff, o que gerou muitas críticas por parte de suas/seus apoiadoras/es da area de educação.

Nesse cenário notamos a fragilidade do ensino de filosofia, e os problemas que nós professoras/es encontramos, pois apesar da 
Filosofia, ser uma disciplina que promove debates, e deveria ampliar uma criticidade, pouco temos visto, nossas/os jovens tomar espaços públicos, promover discussões e sentir-se pertencente a problemas sociais que vivemos, até mesmo dentro da escola. Deixando um grande desafio para nós, de como a filosofia, nos ajuda repensar os espaços que ocupamos, de tornarmos protagonistas e fazer filosofia a partir de nós, (EU-TU, EU-E-TANTOS-OUTROS), respeitando a alteridade e os direitos humanos.

Segundo o professor Severino:

Cabe à Filosofia, nessa situação pedagógica, fornecer subsídios para que o adolescente insira sua experiência pessoal na experiência coletiva, uma vez que é dessa sociedade, historicamente determinada, que ele precisa participar. É aí que poderá realizar sua efetiva cidadania. (SEVERINO, 2010, p.70)

Parece-me, que só compreendemos a escola com a estrutura de dispositivo de poder, que nos ensina cumprir horário, preencher fichas, se portar em sociedade, que controla corpos e modela pensamentos. Será mesmo que a escola tem de se restringir ao educar corpos, para a vida trabalhista?Será que seus projetos de vida (algo tão falado nas escolas estaduais de SP em 2020) só pode ser voltado ao trabalho? Será que a escola não deve nos fazer repensar as nossas relações e a valorização da vida?

Entendo que a existência humana está imbricada na sociabilidade e afetividade. Como o ensino de filosofia pode e deve contribuir com isso é o que precisamos descobrir. A obra "Eu e Tu" de Martin Buber, junto da obra "Entre Nós" de Emmanuel Lévinas, e algumas obras de Paulo Freire nos fazem refletir sobre o que é o educar no pensamento ético, de alteridade e de libertação.

E aqui pretendo refletir a escola, e esses modos de fazer o ensino de filosofia, por meio da ética da alteridade, do diálogo, da valorização e reconhecimento dos direitos humanos. 


\section{Alteridade: a Relação eU - TU}

Todos nós fazemos pré-julgamentos, todos os dias, sempre que olhamos para algo novo, ou alguém. Esse julgamento parte das nossas pré-concepções (culturais), ou de experiências anteriores, no entanto nada tem a ver com aquilo ou aquele que se mostra pra nós naquele momento. Desta maneira julgamos as pessoas, nossas/os estudantes, com base em seus comportamentos, modos de vestir, sotaques, nacionalidade, religião ou qualquer outro modo que se portam em sociedade.

E essa postura, faz com reduzamos esse TU (OUTRA/0), as nossas expectativas, a nós mesmos, qual eu suprassumo a/o OUTRA/0, qual a/o OUTRA/O é apenas a extensão de mim, uma negação daquilo que sou, e as relações só se constituem por dependência. $\mathrm{O}$ que Martim Buber, define como uma relaçã EU-ISSO, o isso performa a coisa, o objeto.

A dialética freiriana vai contra a dialética hegeliana. No pensamento de Freire, inspirado em Buber, a relação pode ser libertadora, e essa libertação ocorre de forma dialógica.

Em sua obra "Educação como Prática de Liberdade" Freire explicita o que é para ele o diálogo:

E que é o diálogo? É uma relação horizontal de A com B. Nasce de uma matriz crítica e gera criticidade (Jaspers). Nutre-se do amor, da humildade, da esperança, da fé, da confiança. Por isso, só o diálogo comunica. E quando os dois pólos do diálogo se ligam assim, com amor, com esperança, com fé um no outro, se fazem críticos na busca de algo. Instala-se então, uma relação de simpatia entre ambos. Só aí há comunicação (FREIRE, 1994, p.115).

Paulo Freire assim como Martin Buber acredita no conhecimento através do diálogo, ou da comunicação, o mundo social e humano, não existiria como tal se não fosse um mundo de comunicabilidade fora do qual é impossível dar-se o conhecimento humano. (FREIRE, 2006, p. 65).

Com sua condição de ser inacabado, completa-se a partir de seus questionamentos e o deixar-se questionar e dando o sentido de sua existência com o outro e com o mundo. Assim como podemos ver na Pedagogia da Autonomia: 
A razão ética da abertura, seu fundamento político, sua referência pedagógica; a boniteza que há nela como viabilidade do diálogo. A experiência da abertura como experiência fundante do ser inacabado. Seria impossível saber-se inacabado e não se abrir ao mundo e aos outros à procura de explicação, de respostas a múltiplas perguntas. 0 fechamento ao mundo e aos outros se torna transgressão ao impulso natural da incompletude. 0 sujeito que se abre ao mundo e aos outros inaugura com seu gesto a relação dialógica em que se confirma como inquietação e curiosidade, como inconclusão em permanente movimento na História (FREIRE, 1997, p. 153-154).

Nessas palavras, Paulo Freire indica também a condição do ser humano enquanto ser que busca a percepção e compreensão do mundo, e isso não ocorre sozinho, em solidão, mas na capacidade de nos relacionarmos com o outro e com o mundo, criando um ser de diálogo.

0 diálogo em Freire concretiza-se em atos de amor, de humildade, de fé, de confiança, de esperança. Buber também fala desse amor, não coisificar o outro é um ato de amor, é reconhecê-lo como outro (como Tu), e não como objeto, coisa.

A alteridade essencial se instaura somente na relação Eu-Tu; no relacionamento Eu-Isso o outro não é encontrado como outro em sua alteridade. Na relação dialógica estão na "presença" o Eu como pessoa e o Tu como outro. (BUBER, 2001, p. 29)

Emmanuel Lévinas apesar de não ter escrito um texto específico sobre educação, penso que no que se refere à racionalidade ética, este filósofo pode contribuir para se repensar a nossa realidade no espaço escolar, junto de Buber e Freire.

A filosofia tradicional, sempre esteve em busca da ontologia, do conhecimento do que é o ser. Emmanuel Lévinas se preocupa com o SER ético, e como SER ético com a/o OUTRA/O? OUTRA/O que não conheço em sua totalidade, e que não poderei reconhecer encaixando em categorias, ou a partir das minhas experiências com o mundo.

Emmanuel Lévinas tem por objetivo romper com a ética da filosofia ocidental. Para o filosofo, nossa ética é excludente, uma vez que criamos um Outro, e o categorizamos: bárbaro, não-humano, pagão, 
herege, pecador, etc. Categorias que não levam em consideração a alteridade do Outro, suas singularidades. Que só conseguimos julgar a partir de pontos de vista dos nossos umbigos, como se estes fosse 0 modelo ideal.

Lévinas defende uma ética baseada na acolhida, na relação "face a face". Mesmo que esse Outro seja diferente de mim, daquilo que acredito e defendo. Ela(e) é um ser de direitos como eu. Independente de sua etnia, religião, gênero ou classe.

Outrem permanece infinitamente transcendente, infinitamente estranho, mas o seu rosto, onde se dá a sua epifania e que apela a mim, rompe com o mundo que nos pode ser comum e cujas virtualidades se inscrevem na nossa natureza e que desenvolvemos também na nossa existência|| (LÉVINAS, 1988, p.173)

Não posso falar de um(a) estudante pelas coisas que alguns dizem sobre ela(e), não posso categorizar um menino, por ele ter trejeitos taxados como femininos, não posso julgar a mulher agredida, a senhora que deixou de estudar porque o marido a proibiu. E nunca poderei dizer que conheço a/o OUTRA/O pelas coisas que dizem, nem mesmo por anos de contato, nunca conhecerei a/o OUTRA/O em sua totalidade.

FACE A FACE eu não posso reduzir a/o OUTRA/O, a uma categoria, a uma experiência. Mas podemos compreender a relação de alteridade, que para Emanuel Lévinas é o verdadeiro sentido ético, que não pode ser dado através da ontologia, mas na relação, na compreensão de outros mundos:

A relação com outrem, portanto não é ontológica. Este vínculo com outrem que não se reduz à representação de outrem, mas à sua invocação, e onde a invocação não é precedida de compreensão. (LÉVINAS, 2004, p.29)

Para Lévinas a ontologia cria sistemas e totaliza a/o OUTRA/0. Rompendo com a totalidade de Hegel, e a ontologia de Heidegger, Lévinas, está na contramão da filosofia européia, fazendo uma filosofia a partir das singularidades. Na qual, através da FACE, me lanço ao outro lutando por justiça, e essa FACE me lança a outra(s) FACE(S) muitas vezes desconhecidas e distantes. 
Essa preocupação com o outro de Lévinas, me faz lembrar da máxima de Jesus Cristo "Amar o próximo como a ti mesmo", de fato é algo muito bonito, mas como amar alguém que não tenho contato algum? Como amar uma pessoa que passou por mim numa calçada movimentada e nem o teu nome eu sei? Como amar o pedinte do farol, ou alguém que eu nunca me encontrei? Como lutar pelos direitos dessas pessoas?

Parece-me que por estar fora desse pensamento semita, e dentro da lógica européia, linear, da busca do sentindo para o ser, de sua totalidade não conseguimos compreender esse pensamento, entretanto, as leituras de Martin Buber, Emmanuel Lévinas e Paulo Freire (um buberiano) são necessárias para sairmos da inércia, e pensarmos na/o OUTRA/O. Apesar de Lévinas não mencionar a que FACE devo me lançar, essas respostas podem ser encontradas no dia a dia. Talvez na face das/os discentes que tanto julgamos e jogamos no campo dos infames: o negro, a mulher, o transexual, o assexuado, o mal vestido, o afeminado, o cadeirante, a masculinizada, a bissexual (indecisa), o viciado, o que tem o pai alcoólatra, a abandonada, a abusada; na face daquela -senhorinha que seu maior sonho sempre foi aprender a ler, na face do discente com paralisia cerebral que todos os dias nos faz as mesmas perguntas, na face da estudante agredida pelo marido na porta da escola, e tantas outras faces que tiveram os direitos humanos negados, extirpados e violados. Na face destes, me lanço a tantas outras faces, a tantas outras pessoas que eu nunca enxerguei os olhos, ou -ouvi seus gritos, mas sei que elas (re) existem.

E ainda me faz refletir, de como buscar nessas relações uma nova compreensão de mundo que não permita que outras pessoas apenas sobrevivam, que tenham o direito de VIVER, de EXISTIR, que ninguém se ache dono do Outro, da razão e do(s) direito(s) desse outro. Que não sinta-se no direito de agredir este Outro por não ter um modo de vida como seu, um modo de vida que você acredite ser o correto.

Compreendo como Lévinas que é no face a face que eu reconheço o(a) outro(a). E arrisco dizer que só pensando no(a) outro(a) como um ser de direitos como eu e como as pessoas que amo, quecompreenderemos que temos responsabilidades com o mundo. Nós enquanto educadores, somos responsáveis em repensar esse mundo, e repensa-lo 
ao lado das/os estudantes, estudante(s) que é/são a(s) FACE(S) mais próxima, e tem muito a nos ensinar.

\section{O EXERCíCIO DA ALTERIDAdE PARA UMA EDUCAÇÃo LIBERTADORA} EM DEFESA DOS DIREITOS HUMANOS - EXPERIÊNCIAS DIDÁTICAS

A arte sempre foi uma grande aliada em sala de aula, em escolas que nos faltam recursos, e espaços diferenciados, a arte possibilita reflexões e processos extraordinários, pois ela esta inserida em nosso cotidiano em diversos lugares e aspectos.

A linguagem das artes propicia um conhecimento universal, pois da periferia as grandes elites, todos já tiveram algum contato com a arte, seja a arte marginal ou a arte clássica. Ainda que muitos não tenham recursos e acesso a museus, a arte esta presente em praças, parques e espaços públicos no qual todos tem acesso. Portanto, ao mencionar uma obra, esta contribue com uma reflexão e possibilita a construção do conhecimento, que outras áreas não conseguem proporcionar.

Tenho por habito trabalhar as datas como Dia Internacional da Mulher, e Consciência Negra, e sempre utilizo a arte para dar inicio ao Diálogo. Em 2018 trabalhei em sala de aula duas mulheres importantíssimas, refletindo o dia 8 de março: Nise da Silveira (Psicanalista e percussora da Luta Antimanicomial), e Carolina de Jesus (poetisa da favela de Canindé.)

Para caminhar com esses dois grandes nomes, recorri às artes; para falar da Nise, trouxe o filme "Nise - O Coração da Loucura", e imagens de uma exposição que ocorreu no Itaú Cultural.

Sobre Carolina de Jesus, trabalhamos "O quarto do despejo", um fragmento da obra, e a música em sua homenagem do grupo musical ILÚ OBÁ DE MIN.

Por meio desta experiência, nota-se que só cita-las, e narrar suas histórias não teriam o mesmo impacto que as obras de arte causaram, portanto, ao falar sobre a vida dessas mulheres, as artes possibilitaram que sentíssemos um pouco do que estas mulheres viveram. Percebemos o quanto dos direitos humanos foram negados naqueles contexto. Negados a Nise quando foi presa. Negados aos internados psiquiatricos. Negados a Carolina Maria de Jesus e aos seus. 
Em 1948, quando começaram a demolir as casas térreas para construir os edifícios, nós, os pobres que residíamos nas habitações coletivas, fomos despejados e ficamos residindo debaixo das pontes. É por isso que eu denomino que a favela é o quarto de despejo de uma cidade. Nós, os pobres, somos os trastes velhos. (JESUS, 1960, p.54)

Essas obras possibilitaram conteúdos para diversas outras aulas, que não falavam apenas da Mulher, mas, de contextos políticos, de desigualdade social, racial, de gênero, liberdade e outros conceitos filosóficos, etc.

Por meio da filosofia e da arte temos como anseio promover a livre associação das ideias na discussão em grupo. A leitura expande o universo cultural, social e afetivo do adolescente, ampliando também o conhecimento de si, sua autoconfiança, seu respeito pelas instituições, pelos direitos humanos e sua cidadania.

Através de obras literárias ou teatrais que retratem o cotidiano e a realidade escolar, onde as/os estudantes se reconheçam na peça e com mundo que os cerca o teatro pode lhes dar a oportunidade de expressar suas ideias sociais e seus sentimentos. Em contra partida, o teatro poderá lhes passar lições éticas e inspirar confiança em melhorar sua própria condição humana e social.

Por meio das artes é possível trabalhar temas transversais, tratando questões como Cidadania, Sexualidade, Drogas, DST (AIDS), Família, Estatuto da Criança e Adolescente.

Um dos conceitos que nos dedicamos ao longo do ano foi "banalidade do mal" da filosofa alemã Hannah Arendt. Ao propor que as/os discentes elaborassem um texto disssertativo sobre os males que são banalizados em nossa sociedade, e estabelecessem um diálogo com a filósofa, percebemos estas/es discentes exercitando a alteridade e o reconhecimento dos direitos humanos.

Em Novembro de 2018, começamos esse exercício solicitei que após a escrita apresentassem para a sala o tema escolhido.

A discente K. R., trouxe o tema -Moradores de Rua e passou a expor porque estes em seu entendimento obtinham uma condição humana banalizada. 
...Aqui bem próximo de nós, encontramos diversos moradores de rua, às vezes some um, mas logo aparece outro. Ninguém pergunta qual foi seu destino? Ou como foram parar ali? No ano passado (2017), só nos primeiros seis meses do ano, 195 moradores de rua foram assassinados no Brasil.

E nós o que fazemos? Viramos a cara? Muitos acham que ali é o lugar dele, que é lá que deve estar, está assim porque quis. É o seu destino. E o que nós temos a ver com isso? Quantas vezes repudiamos os direitos humanos? Quantas vezes não percebemos que direitos humanos é o mínimo (K.R, 16 anos, discente do 2ํㅡㄹ Ano E.M, de uma escola pública periférica de São Bernardo do Campo).

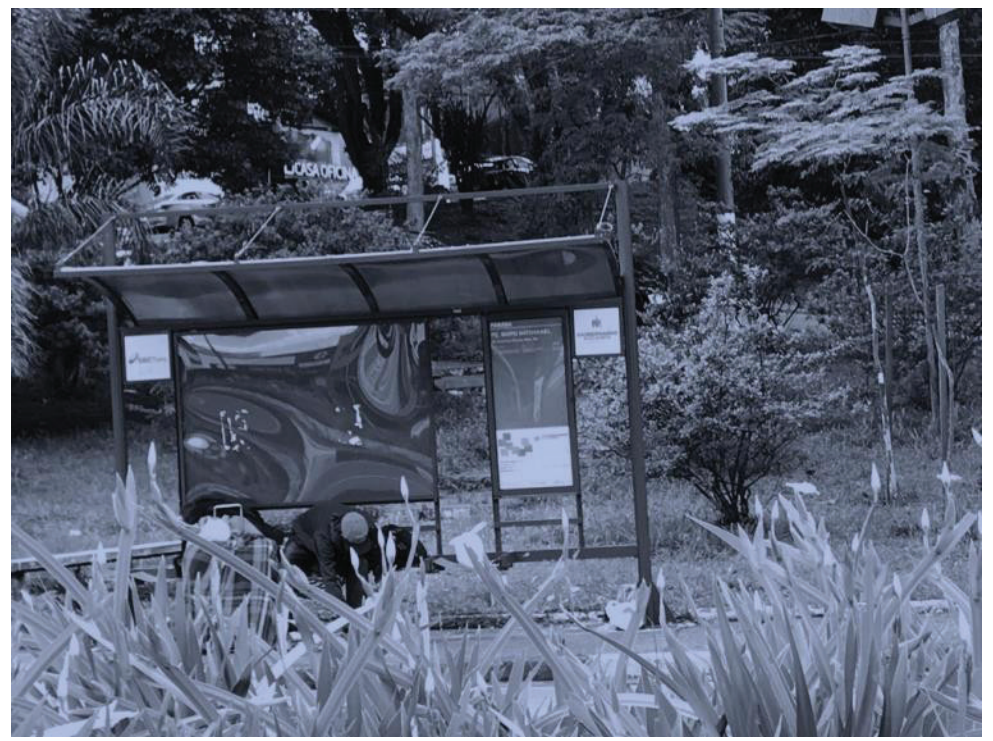

Figura 1: Moradoras/es de Rua.

Neste exercício podemos notar o exercício da alteridade, a K.R. traz em sua fala uma noção da ética da alteridade, de se colocar no lugar da/o OUTRA/O, de reconhecer essa/e OUTRA/O como um de nós, com os mesmo direitos, com necessidades e anseios.

A sala de aula nos proporciona diversas situações de intolerância. Racismo, Bullyng, Xenofobia, Homofobia, Transfobia, Machismo, Intolerância Religiosa e tantas outras formas de opressão, e desrepeitos aos direitos que não se resumem a vida escolar. Situações estas que 
nos tiram do eixo muitas vezes, e nos faz tomar partido, e postura de indagações, para que a/o discente reflita sua fala, e seu comportamento.

Em 2015, passei por uma situação que me faz refletir até hoje. Ministrando o conteúdo de filosofia da religião, para uma turma de terceiro ano, conteúdo proposto pelo Currículo do Estado de SP. Capitulo intitulado Filosofia e Religião, inicia falando da relação Filosofia e Mitologia, e Filosofia e Religião. Muitos das/os discentes presentes compreendiam a filosofia como ruptura com a Mitologia, e não em diálogo. Importante ressaltar que era meu primeiro ano com a turma.

0 assunto religião os instigavam, entre católicos, evangélicos, uma umbandista e um ateu, começava a discussão; acho que foi a primeira vez que encontrei ânimos tão exaltados entre poucas/os discentes, tentava conte-los, porém, os discursos e argumentos eram muito interessantes, entretanto, todos queriam empurrar sua fé e opniões, como verdade absoluta.

Em meio às discussões lembrei-me de um livro, "São Manuel Bueno, Mártir", do filósofo espanhol Miguel de Unamuno. Propus que lêssemos no intervalo dos dias que teríamos até as próximas aulas, e que cada um trouxesse aquilo que mais chamasse atenção no texto.

Na semana seguinte, comecei a aula perguntando sobre o livro. Algum(a)s falaram sobre o que estava achando, sobre o contexto e algumas questões que mais tinha haver com o contexto histórico do que a religião propriamente. 0 discente que se dizia ateu permaneceu calado, perguntei se ele tinha algo a dizer, e ele só acenou um "não" com a cabeça.

No fim da aula, após a saída dos colegas, ele veio até a mesa com o livro em mãos e leu um trecho para mim:

... Estou aqui para fazer viver as almas de meus paroquianos, para fazê-los felizes, para fazer com que sonhem ser imortais, e não para mata-los. É preciso que vivam saudavelmente, com unanimidade de sentido, e isso não poderiam fazer com a verdade, com a minha verdade. Que vivam. Nisso a igreja acerta: faz com que vivam. Religião verdadeira? Todas são verdadeiras enquanto fazem viver espiritualmente os povos que professam, enquanto os consolam por terem nascido para morrer, e para cada povo a religião mais verdadeira é a dele mesmo, aquela que o fez. A minha? A minha é me consolar consolando os demais, embora o conselho que lhes dou não me sirva. (UNAMUNO, 1999, p. 42 e 43.) 
E disse:

- Pro, eu não tenho direito de dizer para meus amigos e para minha mãe que deus não existe, vocês não tem culpa de eu não acreditar no deus de vocês. A minha mãe parece o povo dessa igreja aí, tá enganada, mas, tá feliz! Meu pai foi embora, e deus não me ajudou, mas deve ter ajudado ela, porque ela jura que ele vai me salvar. (L.S, 17 anos, discente do $3^{\circ}$ Ano E.M, de uma escola pública de Santo André)

Não tive palavras para responde-lo, mas, vi uma relação construída no face a face, sabia que a partir daquele momento, o L.S. se lançaria a outra(s) FACE(S), e pensando no dom Manuel.

A atitude em relação às obras propostas em sala não é de crítica ou discussão literária, mas de reverência e identificação.

Desta forma pretende-se desmistificar o ensino escolar formal fazendo com que seja facilitada em muito as pesquisas escolares dos nossos jovens. Despertar o interesse pelo teatro e pela literatura. Em um país com baixo índice de leitores e e acesso as diversas artes é necessário essa apresentação e apreciação para que o país encontre o caminho da promoção das humanidades e se afaste da barbárie, são necessárias medidas urgentes e concretas, se aposta na formação desses jovens; para que possam, por seus próprios esforços, lutar por uma melhor qualidade de vida e conquista de sua cidadania. Busco o universo primário da obra para que as (os) participantes sintam emoções no contato com a peça e a partir delas possam dar significado ao mundo, aprendendo a se relacionar com os outros e consigo mesmo.

No texto "A importância do Ato de ler" Paulo Freire nos chama atenção para isto: "integrada ao nosso tempo e ao nosso espaço e levando ao homem refletir sobre sua ontológica vocação de ser sujeito" (FREIRE, 2006, p.114).

A partir da obra "O Alienista", Machado de Assis fizemos diálogo com nossa realidade, como o discurso tem poder, dialogando com o filósofo Michel Foucault e o conceito saber-poder. Assim como Simão Bacamarte tem poder sobre uma cidade, quantos conduzem nossas práticas todos os dias?

A seguir podemos ver algumas releituras dos discentes do primeiro ano do ensino médio, em diálogo com nossa realidade. 


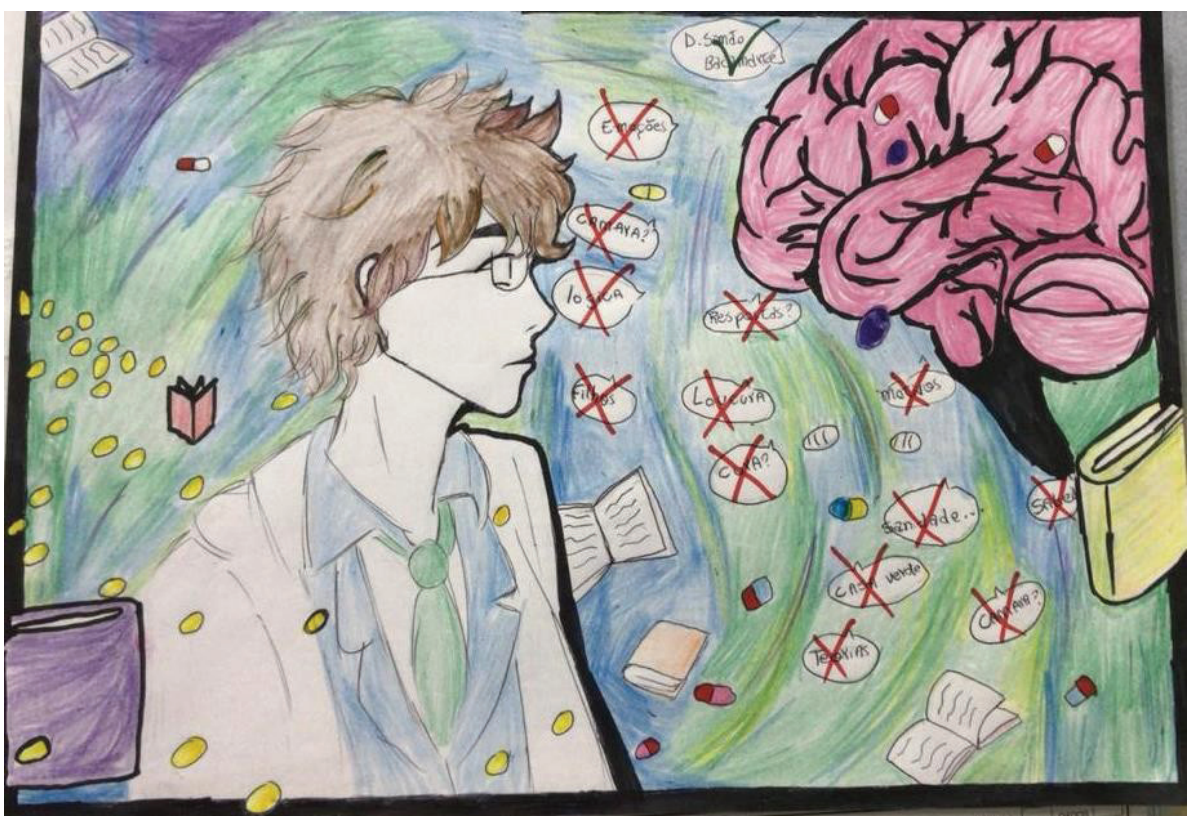

Figura 2: Releitura - 0 Alienista - Machado de Assis E. P. - Discente do 1ํ Ano do Ensino Médio

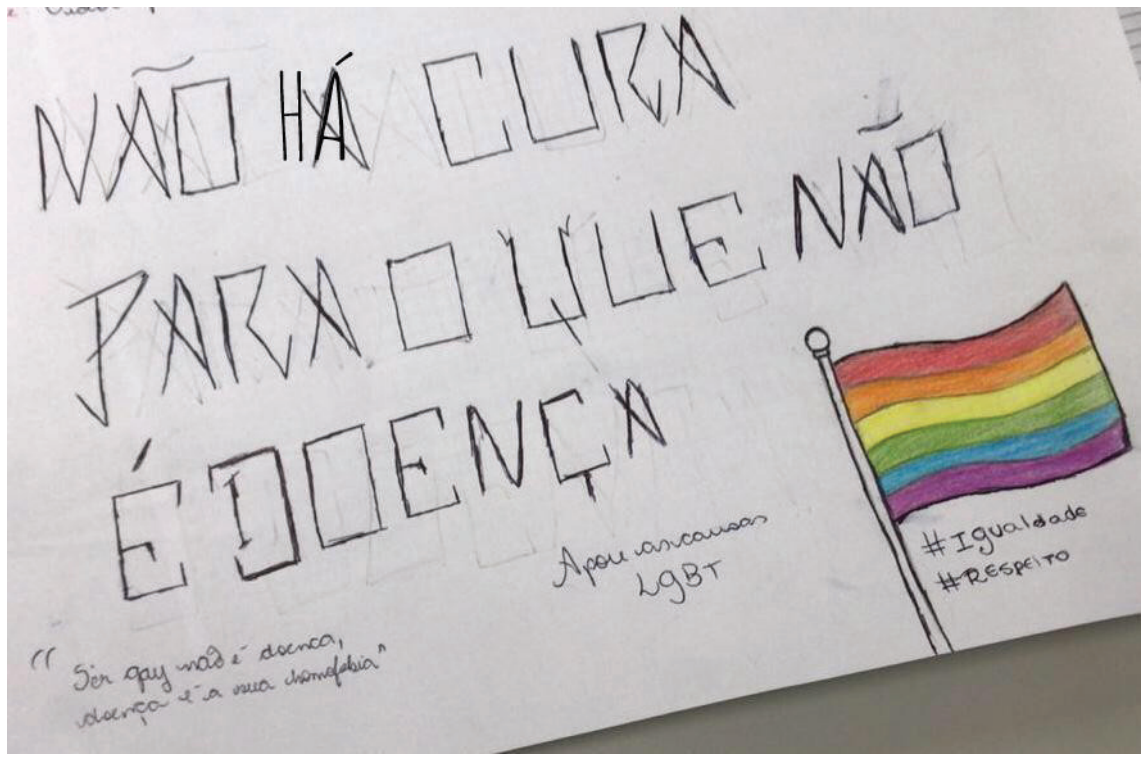

Figura 3: Fotografia da Releitura - 0 Alienista - Machado de Assis

V. G. - Discente do 1ํ Ano do Ensino Médio

Revista Páginas de Filosofia, v. 9, n. 2, p. 201-219, jul.-dez. 2020 
Uma outra obra que debatemos em sala de aula foi a poesia "Rosa de Hiroshima", de Vinicius de Moraes:

\section{A Rosa de Hiroxima}

Pensem nas crianças mudas telepáticas / Pensem nas meninas cegas inexatas / Pensem nas mulheres rotas alteradas / Pensem nas feridas como rosas cálidas / Mas oh não se esqueçam da rosa da rosa / Da rosa de Hiroxima / A rosa hereditária / A rosa radioativa estúpida e inválida / A rosa com cirrose / A antirrosa atômica / Sem cor sem perfume / Sem rosa sem nada.

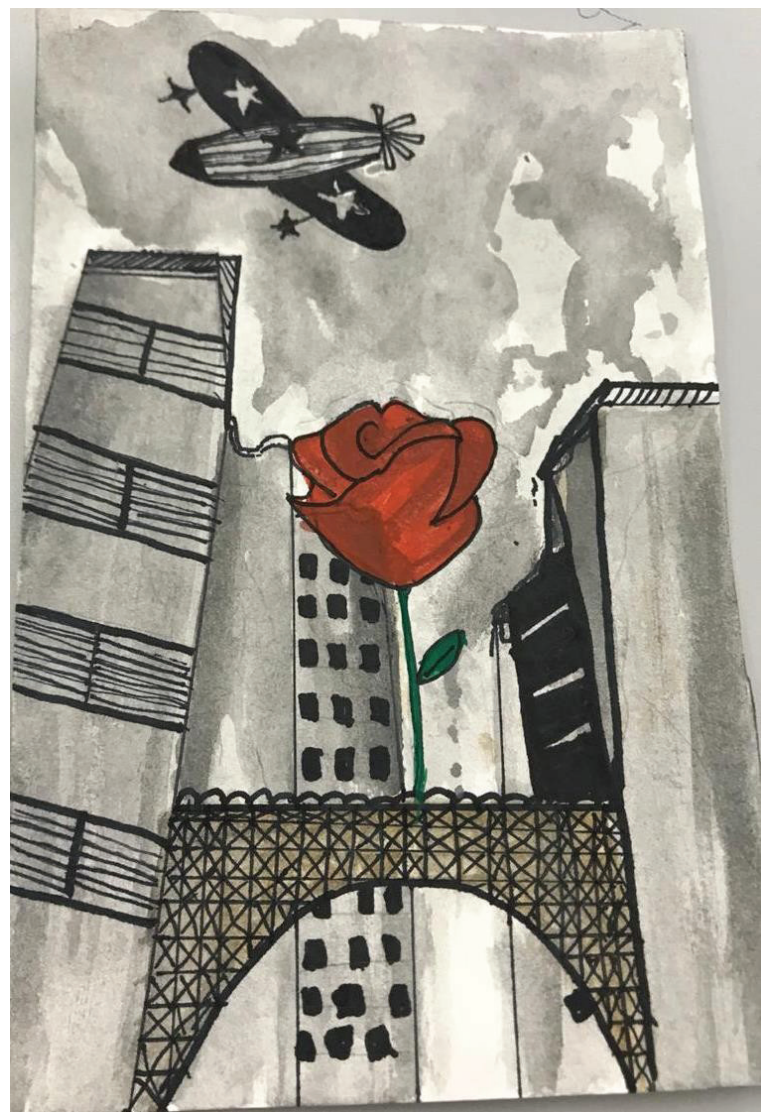

Figura 4: Fotografia do desenho em Aquarela. Releitura - Rosa de Hiroshima -

Vinicius de Moraes - G.F. - Discente do 1ํAno do Ensino Médio

Revista Páginas de Filosofia, v. 9, n. 2, p. 201-219, jul.-dez. 2020 
A partir das obras de arte, podemos questionar e criar rupturas em nossas sociedade. Questionar a condição social e humana dos povos originários, do povo negro, da mulher, do ex- presidiário, deficientes físicos e intelectuais, população LGBTTQIA+ e de tantos outros grupos que se encontram a margem da sociedade. Pensar e defender os direitos de toda sociedade, sobretudo as minorias.

Em nossas aulas, partimos do diálogo, da escuta e da troca. Penso que o ensino de filosofia, seja nos espaços formais ou informais, está sempre relacionado à fala e a escuta. Mas não falamos de qualquer escuta, uma escuta de verdadeiro encontro com a/o OUTRA/0, de interesse pelo pensamento da/o OUTRA/0, pois do contrário, a relação EU-TU / professor-aluno pode fazer com que o pensamento do primeiro, anule o pensamento da/o OUTRA/0, indo contra a perspectiva de alteridade.

Através desse método filosófico, podemos vivenciar essa experiência ética que se expandirá para outros espaços, construindo novos mundos, novos modos de existência e resistências.

\section{CONSIDERAÇões FINAIS}

Este artigo teve por objetivo pensar o papel do ensino de filosofia na reinvenção do espaço escolar em perspectiva da alteridade e dos direitos humanos. Mais do que conceitos e teorias filosóficas, pretendia-se mostrar as práticas de ensino de filosofia, que contribuem para a compreensão das singularidades, na construção das relações e do próprio espaço da instituição escola.

Isso quer dizer, que o essencial aqui, não é o assunto norteador, a habilidade ou competência a ser desenvolvida, mas a forma como trabalhamos esses assuntos.

A ética da Alteridade, tem por essência pensar as relações, os outros, rompendo com a lógica hegeliana, pensando e exercendo melhor a sociabilidade e afetividade, como diria Fernando Pessoa "é um esforço de aprender a desaprender" e neste processo de 2015 a 2018, encontrei uma comunidade estudantil disposta a esse exercício.

A arte foi o caminho que encontrei para repensar nossos modos de ser no mundo, e como somos construídos. Se Foucault, nos chama atenção para escola disciplinadora, como podemos sair dessa estrutura, 
e sermos seres além do que nos é imposto? Se os corpos infantis são alvos do biopoder, e nós professoras e professores somos mecanismos desse biopoder, como criar resistências em sala de aula?

Manoel de Barros, poeta e filósofo brasileiro com seu personagem, Bernardo o andarilho, que ilustra a epigrafe deste trabalho, nos faz pensar sobre sua condição no mundo e seus anseios, não é porque nasci -árvore que preciso ser -árvore para sempre. Outras poesias nos mostram a imobilidade do Bernardo, mas, isso não o impediu de se tornar o arãquã que tanto sonhou.

Algum(a)s estudantes compreenderam que a frase "ele bateu asas e avoou" (BARROS, 2010, p.476), fora sua passagem, sua morte, e isso causou uma nova problematização, será que só é possível nos libertarmos dos modos de vida institucionalizados após a morte?

O problema que foi um ponto de partida, para esse trabalho, me trouxe novos questionamentos e a(o)s discentes que participaram deste processo, e acredito que este é o movimento para o estudo filosófico, não se acomodar, viver a inquietude diante dos elementos e vivências cotidianas. Possibilitando novas pesquisas, e outros caminhos para pensar os nossos modos de vida, sendo resistência e sempre em defesa do direito de todas, todos e todes.

\section{REFERÊNCIAS}

\section{Principais:}

ADORNO, T. Educação e Emancipação. Tradução Wolfgang Leo Maar. 2. Ed. Rio de Janeiro: Paz e Terra, 1995.

BUBER, M. Eu e tu. São Paulo: Centauro, 2001.

CASTRO, E. Vocabulário de Foucault $1^{\underline{a}}$ Ed. Rio de Janeiro: Forense Universitária, 2011 FREIRE, P. Educação como prática da liberdade. Rio de Janeiro: Paz e Terra, 1994

_. Extensão ou Comunicação? 13. ed. Rio de Janeiro: Paz e Terra, 2006.

_. Pedagogia da Autonomia: saberes necessários à prática educativa. São Paulo: Paz e Terra, 1997.

_. Pedagogia do Oprimido. Rio de Janeiro: Paz e Terra, 1987. 
FOUCAUlT, M. O Nascimento da Biopolítica. (1978-1979). [tradução de Eduardo Brandão]. São Paulo: Martins Fontes, 2008.

_. Vigiar e Punir. 6ª Ed. Petrópolis: Vozes, 1987.

_. Em defesa da sociedade. Tradução de Maria Ermantina Galvão. São Paulo: Martins Fontes, 1999

GHEDIN, Evandro. A problemática da Filosofia no Ensino Médio. In: FÁVERO, Altair Alberto; RAUBER, Jaime José; KOHAN, Walter Omar (Org.). Um olhar sobre o ensino de Filosofia. Ijuí: Unijuí, 2002. p. 209-234.

LÉVINAS, E. Entre Nós - Ensaios sobre a alteridade. Petrópolis: Vozes, 2004.

—. Totalidade e infinito, Lisboa, Edições 70, 1988

\section{Complementares:}

BARROS, Manoel de. Poesia completa. São Paulo: Leya, 2010.

UNAMUNO, M. São Manuel Bueno, Mártir. São Paulo: L\&PM, 1999.

Revista Páginas de Filosofia, v. 9, n. 2, p. 201-219, jul.-dez. 2020 